\title{
PENGARUH PENGEMBANGAN PRODUK DAN MEDIA SOSIAL TERHADAP KEPUTUSAN PEMBELIAN (SURVEI PADA PELANGGAN WEDDING PLANNER CASTURIA PHOTOGRAPHY BANDUNG)
}

\author{
Ridwani Fauziahdewi ${ }^{1}$, Taufik Zulfikar ${ }^{2}$ \\ ${ }^{1,2}$ Universitas Sangga Buana Bandung \\ ${ }^{2}$ korespondensi : taufikzulfikar16@gmail.com
}

\begin{abstract}
When it is like now, wedding services must change their services according to the restrictions set by the government, as well as how to communicate these service products. Product innovation and social media are the marketing strategies of Casturia photography to influence the purchasing decision process of its customers. This study aims to study the effect of product development and social media on purchasing decisions. The research method used is quantitative with multiple linear regression analysis tools. The sample of this research is 96 customers of Casturia photography. The results show that there is a positive and significant influence on product development and social media on purchasing decisions either partially or simultaneously.
\end{abstract}

Keyword : Product innovation, Social media, Purchase decision

\begin{abstract}
ABSTRAK
Saat pademi seperti sekarang ini jasa layanan pernikahan harus merubah jasa layanannya disesuaikan dengan batasan-batasan yang di atur oleh pemerintah, begitu juga dengan cara mengkomunikasikan produk layanan tesebut. Pengembangan produk dan media sosial menjadi strategi pemasaran dari Casturia photography untuk mempengaruhi proses keputusan pembelian dari pelanggannya. Penelitian ini bertujuan untuk mempelajari pengaruh pemgembangan produk dan media sosial terhadap keputusan pembelian. Metode penelitian yang digunakan kuantitatif dengan alat analisis regresi linear berganda. Sample penelitian ini adalah pelanggan Casturia photography sebanyak 96 orang. Hasil menunjukan bahwa terdapat pengaruh positif dan signifikan pengembangan produk dan media sosial terhadap keputusan pembelian baik secara parsial maupun simultan.
\end{abstract}

Kata Kunci : Pengembangan produk, Media sosial, Keputusan pembelian

\section{PENDAHULUAN}

Saat pandemic seperti sekarang ini merubah perilaku orang dalam mengambil keputusan pembelian, begitu juga yang terjadi dalam perilaku orang dalam mengadakan pesta pernikahan yang disebabkan banyaknya pembatasan yang dilakukan oleh pemerintah.

Casturia photography sebagai organiser pernikahan harus memperbaharui atau mengembangkan jasa layanannya disesuaikan dengan kondisi pandemi. Jasa layanan yang ditawarkan oleh Casturia photography sudah dikembangkan mengikuti kebutuhan dan keinginan pelangan sehingga dapat menarik pelanggan dalam proses keputusan pembelian. Keputusan pembelian konsumen adalah kegiatan yang berhubungan langsung dengan memperoleh, mengkonsumsi, dan membuang produk dan layanan, termasuk proses keputusan yang mendahului dan mengikuti tindakan ini. Dalam pelayanan membutuhkan waktu (liburan, perjalanan, pemandu pernikahan dan lain-lain), keputusan membentuk bagian penting dari perilaku konsumen. (J. F. Engel, R. D. Blackwell, and P. W. Miniard dalam [1]. Keputusan pembelian adalah suatu keputusan konsumen sebagai pemilikan tindakan dari dua atau lebih 
pilihan alternatif mengenai proses, cara, perbuatan membeli, dengan mempertimbangkan faktor lain tentang apa yang dibeli, waktu membeli, dimana membeli serta cara pembayarannya (Sumarwan dalam [2]

Media sosial menjadi alat komunikasi dua arah yang efektif saat ini dimana orang cenderung selalu berada di rumah. Casturia photography memanfaat media sosial untuk mengkomunikasikan layanan jasa hasil dari inovasi. Dalam mengambil keputusan pembelian, konsumen akan melalui beberapa tahapan seperti yang dikemukakan Philip Kotler dalam [3] termasuk tahap pencarian informasi dan evaluasi alternatif. Artinya konsumen dihadapkan pada beberapa opsi yang akan dipertimbangkan dalam membuat keputusan pembelian sehingga perusahaan harus memikirkan strategi yang tepat untuk memperkenalkan produk yang akan ditawarkan di pasar sehingga dapat mempengaruhi konsumen untuk membeli produk atau jasa yang ditawarkan oleh perusahaan. Strateginya bisa dengan menyusun dan menciptakan atau mengembangkan produk baru atau jasa baru ditawarkan kepada konsumen.

Inovasi produk atau layanan adalah kemampuan perusahaan untuk meningkatkan desain produk, fitur, atau spesifikasi sesuai keinginan pelanggan atau meningkatkan nilai produk atau layanan dengan menciptakan produk atau layanan baru [4] Inovasi adalah sesuatu yang baru tetapi memiliki beberapa level yang terkait dengan jenis inovasi ini. Ini dibagi menjadi inkremental, radikal, dan revolusioner. Inovasi inkremental adalah inovasi yang mengambil langkah kecil dalam proses inovasi. Radikal Inovasi adalah inovasi yang mengubah hampir segalanya tentang produk, proses, atau organisasi khusus dan inovasi revolusioner adalah inovasi yang menemukan yang baru terobosan yang sebelumnya tidak ada [5]

Casturia photography mengkomunikasikan produk hasil inovasinya melalui Instagram, Whatsapp, dan Facebook dengan target pasar pada kaum muda. Selain itu, hari ini sangat penting untuk mempertimbangkan karakteristik generasi saat ini - Milenial. Mereka adalah audiens media sosial utama yang tidak mudah dipengaruhi oleh media sosial karena 48 persen mengklaim bahwa media sosial tidak pernah memengaruhi keputusan pembelian mereka. Milenial cenderung begitu mengkonsumsi konten di berbagai platform melalui perangkat yang berbeda biasanya sangat dipengaruhi oleh apa yang dipikirkan rekan-rekan mereka. Jadi bagi pemasar, itu penting untuk memahami bagaimana demografis ini mengonsumsi informasi dan kedua, bagaimana menyampaikan pesan pemasaran yang tepat dan menarik mereka (Johson W dalam [6].

Media sosial mengacu pada aktivitas, praktik, dan perilaku di antara komunitas orang yang berkumpul secara online untuk berbagi informasi, pengetahuan dan opini menggunakan media percakapan (aplikasi berbasis web) [7] menjelaskan bahwa review, foto, dan video pada media sosial akan mempengaruhi motivasi konsumen untuk membeli suatu produk. $61,5 \%$ termotivasi dari 
tinjauan sejawat, $51 \%$ termotivasi dari foto / video produk, $38,5 \%$ termotivasi dari komentar konsumen. Media Sosial dapat didefinisikan sebagai sekelompok aplikasi berbasis Internet yang dibangun di atas dasar ideologis dan teknologi dari Web dan yang memungkinkan pembuatan dan pertukaran konten yang dibuat oleh pengguna [8]. Media sosial akan mempengaruhi konsumen dari pencarian informasi hingga perilaku pembelian (Mangold \& Faulds, dalam [9]. McKinsey menemukan itu karena komunikasinya telah diubah dari satu arah pemasar ke konsumen - menuju komunikasi dua arah - pemasar ke konsumen dan konsumen ke pemasar - pemasar membutuhkan cara sistematis untuk memenuhi permintaan konsumen dan mengelola promosi dari mulut ke mulut (Court et al dalam [6]. Penelitian ini bertujuan untuk menganalisa pengaruh pengembangan produk dan media sosial terhadap keputusan pembelian.

\section{TINJAUAN PUSTAKA}

\section{Hubungan pengembangan produk dengan}

\section{keputusan pembelian}

Beberapa penelitian yang mneunjukan hubungan antara pengembangan produk dengan keputusan pembelian adalah penelitian yang dilakukan [4] yang meneliti tentang keputusan pembeli konsumen makanan (kuliner) di Bandung menunjukan bahwa produk makanan yang mengalami inovasi dan kualitas layanan memiliki pengaruh yang signifikan terhadap keputusan pembelian. Inovasi produk yang dilakukan secara ikremental mempunyai pengaruh secara partial terhadap keputusan pembelian demikian hasil penelitian yang dilakukan oleh [5] pada industri kain tenun di Karo. Hasil penelitian yang dilakukan oleh [10] menunjukan hasil bahwa variable inovasi produk dan promosi tidak mempengaruhi variable keputusan pembelian pada produk Lapis Bogor Sangkurian. Berdasarkan analisis bisa disimpulkan, konsumen menggunakan kelima tahap selama proses pengambilan keputusan dalam produk yang dibeli jarang atau sesekali dengan keterlibatan tinggi. Perilaku konsumen terhadap barang atau layanan dengan keterlibatan rendah dalam pengambilan keputusan jika produk tersebut digunakan sehari-hari atau produk berbiaya rendah [11]. Dengan demikian dari penelitianpenelitian terdahulu sebagai studi empiris maka dapat dijadikan hipotesis sebagai berikut :

H1 : Terdapat pengaruh pengembangan produk terhadap keputusan pembelian

\section{Hubungan media sosial dengan keputusan pembelian}

Penelitian-penelitian yang pernah dilakukan tentang hubungan antara media social dengan keputusan pembelian antara lain yang dilakukan oleh [9] yang meneliti tentang keputusan pembelian pada konsumen produk fashion di Semarang menunjukan hasil bahwa media social memiliki pengaruh yang signifikan terhadap keputusan pembelian. Persentase yang sangat tinggi dari pengguna internet untuk mencari informasi mengenai pembelian di internet. Peralatan elektronik, 
hiburan, dan perjalanan adalah pembelian yang paling banyak dicari, demikian hasil penelitian yang ditemukan oleh [12]. [13] menganalisis pengaruh kegiatan media sosial merek dan keterlibatan peesrta media sosial di proses keputusan pembelian konsumen. Temuan kami menunjukkan bahwa keterlibatan dengan fanpage Facebook mempunyai efek positif pada kesadaran merek konsumen, WOM (word of mouth aktivitas dan niat membeli. Dengan demikian dari penelitian-penelitian terdahulu sebagai studi empiris maka dapat dijadikan hipotesis sebagai berikut :

$\mathrm{H} 2$ : Terdapat pengaruh media sosial terhadap keputusan pembelian

H3 : Terdapat pengaruh pengembangan produk dan media sosial terhadap keputusan pembelian secara simultan

\section{METODE PENELITIAN}

Metode penelitian ini adalah metode kuantitatif dengan metode analisis yang digunakan metode deskriptif verifikatif, alat analisis yang digunakan regresi linear berganda.

$\mathrm{Y}=\mathrm{a}+\mathrm{b} 1 \mathrm{x} 1+\mathrm{b} 2 \times 2$

Keterangan:

$\mathrm{a}, \mathrm{b} 1, \mathrm{~b} 2=$ Konstanta

$\mathrm{Y} \quad=$ Keputusan pembelian

$\mathrm{X} 1=$ Pengembangan produk

$\mathrm{X} 2=$ Media sosial

Teknik pengumpulan data dengan menyebarkan kuesioner pertanyaan tertutup kepada responden. Sample dengan menggunakan rumus slovin dengan tingkat kepercayaan $90 \%$ diperoleh sampel sebanyak 96 orang. Sampel yang digunakan adalah pelanggan yang diambil secara simple random.

\section{HASIL DAN PEMBAHASAN}

Profil responden dapat dilihat pada tabel 1

Tabel 1 : Profil Responden

\begin{tabular}{lrr}
\hline \multicolumn{1}{c}{ Keterangan } & Frekuensi & \% \\
\hline Gender : & & \\
Pria & 55 & $57 \%$ \\
Wanita & 41 & $43 \%$ \\
Jumlah & 96 & $100 \%$ \\
Usia : & & \\
$<20$ tahun & 5 & $5,2 \%$ \\
$21-30$ tahun & 69 & $71,9 \%$ \\
$31-40$ tahun & 19 & $19,8 \%$ \\
$>40$ tahun & 3 & $3,1 \%$ \\
Jumlah & 96 & $100 \%$ \\
Profesi & & \\
Mahasiswa & 15 & $15,6 \%$ \\
ASN & 16 & $16,7 \%$ \\
Pegawai Swasta & 30 & $31,3 \%$ \\
Wirausaha & 22 & $22,9 \%$ \\
Lainnya & 13 & $13,5 \%$ \\
Jumlah & 96 & $100 \%$
\end{tabular}

Sumber: data primer yang diolah (2021) 
Responden didominasi oleh pria, rentang usia 97\% di bawah 40 tahun, profesi yang dominan adalah pegawai swasta.
Hasil uji validitas dengan tariff signifikan 5\%, sebagai berikut :

Tabel 2 : Hasil Uji Validitas

\begin{tabular}{|c|c|c|c|c|}
\hline Variabel & No Item & r Hitung & r Tabel 5\% (96) & Keterangan \\
\hline \multirow{7}{*}{$\mathrm{X} 1$} & 1 & 0,383 & 0,1671 & Valid \\
\hline & 2 & 0,679 & 0,1671 & Valid \\
\hline & 3 & 0,700 & 0,1671 & Valid \\
\hline & 4 & 0,727 & 0,1671 & Valid \\
\hline & 5 & 0,616 & 0,1671 & Valid \\
\hline & 6 & 0,732 & 0,1671 & Valid \\
\hline & 7 & 0,675 & 0,1671 & Valid \\
\hline \multirow{7}{*}{$\mathrm{X} 2$} & 8 & 0,755 & 0,1671 & Valid \\
\hline & 9 & 0,787 & 0,1671 & Valid \\
\hline & 10 & 0.747 & 0,1671 & Valid \\
\hline & 11 & 0,790 & 0,1671 & Valid \\
\hline & 12 & 0,708 & 0,1671 & Valid \\
\hline & 13 & 0.793 & 0,1671 & Valid \\
\hline & 14 & 0,795 & 0,1671 & Valid \\
\hline \multirow{7}{*}{$\mathrm{Y}$} & 15 & 0,721 & 0,1671 & Valid \\
\hline & 16 & 0,801 & 0,1671 & Valid \\
\hline & 17 & 0,782 & 0,1671 & Valid \\
\hline & 18 & 0,790 & 0,1671 & Valid \\
\hline & 19 & 0,765 & 0,1671 & Valid \\
\hline & 20 & 0,813 & 0,1671 & Valid \\
\hline & 21 & 0,723 & 0,1671 & Valid \\
\hline
\end{tabular}

Berdasarkan table 2 di atas bahwa data valid Hasil uji reliabilitas, sebagai berikut : dimana $r$ hitung lebih besar dari $r$ table.

Tabel 3 : Hasil uji Reliabilitas

\begin{tabular}{llrr}
\hline No. & \multicolumn{1}{c}{ Keterangan } & Jumlah Item & Cronbach's Alpha \\
\hline 1. & Pengembangan & 7 & .846 \\
2. & produk & 7 & .903 \\
3. & Media social & 7 & .909 \\
& Keputusan & & \\
\multicolumn{4}{c}{ pembelian } \\
\hline \multicolumn{4}{c}{ Sumber: data primer yang sudah diolah, 2021 }
\end{tabular}

Berdasarkan hasil uji reliabilitas diatas penelitian ini reliabel, karena Cronbach's menunjukan bahwa seluruh instrument dalam Alpha $>0,60$. 


\section{Uji Asumsi Klasik}

Telah dilakukan uji normalitas, uji multikolinearitas, uji heterokedasitas, uji korelasi dengan hasil sebagai berikut :

Tabel 4 : Hasil Uji Normalitas One-Sample Kolmogorov-Smirnov Test

\begin{tabular}{llr}
\hline & & $\begin{array}{c}\text { Unstandardize } \\
\text { d Residual }\end{array}$ \\
\hline $\mathrm{N}$ & & 96 \\
Normal Parameters ${ }^{\mathrm{a}, \mathrm{b}}$ & Mean & .0000000 \\
& Std. Deviation & 2.52354365 \\
Most Extreme Differences & Absolute & .068 \\
& Positive & .038 \\
& Negative & -.068 \\
Test Statistic & & .068 \\
Asymp. Sig. (2-tailed) & & $.200^{\mathrm{c}, \mathrm{d}}$ \\
\hline \multicolumn{2}{c}{ Sumber : data primer yang sudah diolah, 2021 }
\end{tabular}

Tabel 4 menunjukan besarnya nilai kolmogrov smirnov adalah 0,200 dengan nilai signifikansi 0,200. karena nilai signifikansi yang dihasilkan oleh kolmogrov smirnov lebih dari atau 5\% (taraf nyata signifikansi penelitian) yaitu $(0,200>0,05)$, maka dapat disimpulkan bahwa Ho diterima atau data residual berdistribusi normal, dengan kata lain model regresi layak dipakai karena memenuhi asumsi normalitas.

\section{Tabel 5 : Analisis interkorelasi}

\begin{tabular}{llrrr}
\hline \multicolumn{5}{c}{ Correlations } \\
\hline Pearson Correlation & $\mathrm{Y}$ & 1.000 & .631 & .676 \\
& $\mathrm{X} 1$ & .631 & 1.000 & .738 \\
& $\mathrm{X} 2$ & .676 & .738 & 1.000 \\
\hline Sig. (1-tailed) & $\mathrm{Y}$ &. & .000 & .000 \\
& $\mathrm{X} 1$ & .000 &. & .000 \\
& $\mathrm{X} 2$ & .000 & .000 &. \\
\hline $\mathrm{N}$ & $\mathrm{Y}$ & 96 & 96 & 96 \\
& $\mathrm{X} 1$ & 96 & 96 & 96 \\
& $\mathrm{X} 2$ & 96 & 96 & 96 \\
\hline \multicolumn{5}{c}{ Sumber : data primer yang sudah diolah, 2021 }
\end{tabular}

Karena nilai 0,738 tersebut kurang dari 0,8 maka gejala multikolinearitas tidak terdeteksi. Pada Tabel 6 confficient dapat anda perhatikan bahwa nilai standar error kurang dari satu, yaitu $\mathrm{X} 1=0,107$ dan $\mathrm{X} 2=0,105$. Maka dapat dikatakan bahwa nilai standar error rendah dan multikolinearitas tidak terdeteksi. 
Tabel 6 : Standar Error Uji Multikolinearitas

\begin{tabular}{|c|c|c|c|c|c|c|}
\hline \multicolumn{7}{|c|}{ Coefficients $^{\mathrm{a}}$} \\
\hline \multirow{2}{*}{ Model } & & \multicolumn{2}{|c|}{$\begin{array}{l}\text { Unstandardized } \\
\text { Coefficients }\end{array}$} & \multirow{2}{*}{$\begin{array}{c}\begin{array}{c}\text { Standardized } \\
\text { Coefficients }\end{array} \\
\text { Beta }\end{array}$} & \multirow{2}{*}{$\mathrm{t}$} & \multirow{2}{*}{ Sig. } \\
\hline & & B & $\begin{array}{l}\text { Std. } \\
\text { Error }\end{array}$ & & & \\
\hline \multirow{3}{*}{1} & (Constant) & 7.081 & 1.919 & & 3.689 & .000 \\
\hline & $\mathrm{X} 1$ & .282 & .107 & .289 & 2.645 & .010 \\
\hline & $\mathrm{X} 2$ & .444 & .105 & .463 & 4.236 & .000 \\
\hline
\end{tabular}

Tabel 7 : Confidence Interval

\begin{tabular}{rcccccc}
\hline \multicolumn{3}{c}{ Coefficients $^{\mathbf{a}}$} \\
\hline $\begin{array}{c}95.0 \% \text { Confidence } \\
\text { Interval for B }\end{array}$ & Correlations & \multicolumn{3}{c}{$\begin{array}{c}\text { Collinearity } \\
\text { Statistics }\end{array}$} \\
\hline $\begin{array}{c}\text { Lower } \\
\text { Bound }\end{array}$ & $\begin{array}{c}\text { Upper } \\
\text { Bound }\end{array}$ & $\begin{array}{c}\text { Zero- } \\
\text { order }\end{array}$ & Partial & Part & $\begin{array}{c}\text { Tolera } \\
\text { nce }\end{array}$ & VIF \\
\hline 3.269 & 10.892 & & & & & \\
\hline .070 & .494 & .631 & .264 & .195 & .455 & 2.199 \\
\hline .236 & .653 & .676 & .402 & .312 & .455 & 2.199 \\
\hline a. Dependent Variable: Y & & & & \\
\hline
\end{tabular}

Pada Tabel 7 menunjukan nilai rentangnya sempit, yaitu pada X1 0,070 sampai dengan 0,494 . Sedang pada $X 2=0,236$ sampai dengan 0,653 . Karena rentangnya sempit maka multilkolinearitas tidak terdeteksi.

Tabel 8 : Collinearity Diagnostics ${ }^{\mathrm{a}}$

\begin{tabular}{llrrrrrr}
\hline & & Condition & \multicolumn{3}{c}{ Variance Proportions } \\
\cline { 5 - 7 } Model & Dimension & Eigenvalue & Index & (Constant) & X1 & X2 \\
\hline 1 & 1 & 2.982 & 1.000 & .00 & .00 & .00 \\
& 2 & .012 & 15.558 & 1.00 & .11 & .15 \\
& 3 & .006 & 23.246 & .00 & .89 & .85 \\
\hline
\end{tabular}

a. Dependent Variable: $\mathrm{Y}$

Tabel 8 menunjukan nilai eigenvalue dan condirtion index di atas dapat dsimpulkan bahwa gejala multikolinearitas terjadi di dalam model regresi. Dalam tabel di atas nilai eigenvalue $0,006<0,01$ dan condition index 23,246 dimana kurang dari 30. 


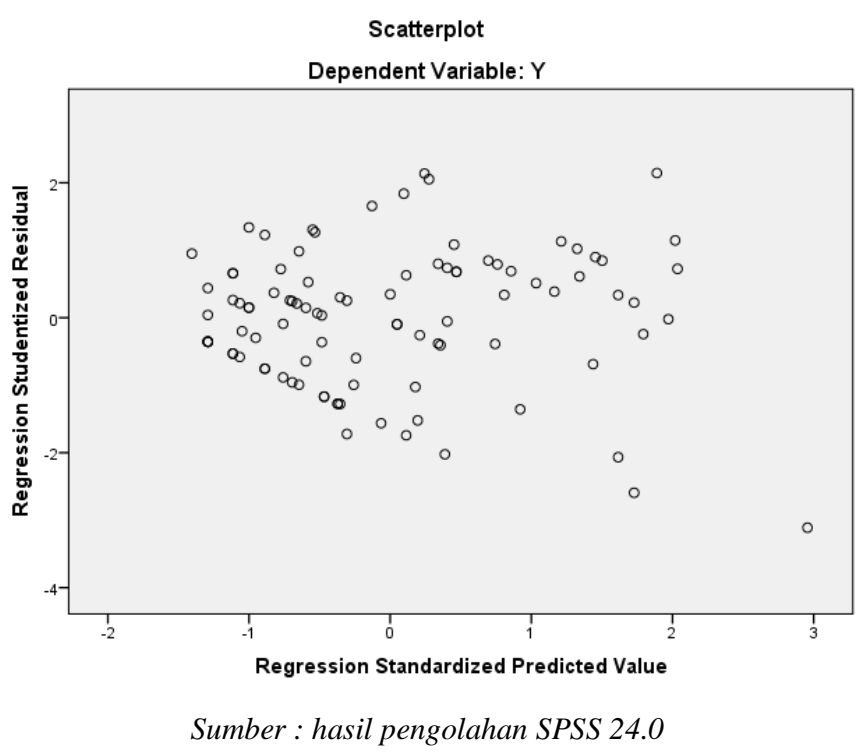

Gambar 1 : Hasil Uji Heteroskedastisitas

Gambar1 menunjukkan bahwa titik-titik tidak membentuk pola tertentu atau tidak ada pola yang jelas serta titik-titik menyebar di atas dan di bawah angka 0 pada sumbu Y, maka tidak terjadi heteroskedastisitas.

\section{Analisa Regresi Linear Berganda}

Berikut ini menunjukkan hasil estimasi model persamaan regresi yang menunjukkan pengaruh pengembangan produk dan media sosial terhadap keputusan pembelian. Berdasarkan hasil perhitungan dengan menggunakan program SPSS versi 24.0 didapat hasil sebagai berikut:

Tabel 9 : Ringkasan analisis Regresi Berganda

\begin{tabular}{lrrr}
\hline Variabel & Koefisien Regresi & t-hitung & \multicolumn{1}{c}{ Sig } \\
\hline Konstanta & 7,081 & & \\
\hline X1 & 0,282 & 2,645 & 0,01 \\
\hline X2 & 0,444 & 4,236 & 0 \\
\hline Fhitung & 45,618 & & 0 \\
\hline R Square & 0,495 & &
\end{tabular}

Sumber : hasil pengolahan SPSS 2

Adapun rumus persamaan regresi dalam analisis atau penelitian ini adalah sebagai berikut: $\quad Y=\mathbf{7 , 0 8 1}+\mathbf{0 , 2 8 2 X 1}+\mathbf{0 , 4 4 4 X 2}$ Dilihat dari tanda pada koefisien regresi (parameter) dalam persamaan regresi linier berganda di atas, variabel koefisien regresi bertanda positif artinya pengaruh variabel bebas terhadap variabel terikat adalah searah. Tanda positif pada koefisien regresi berarti pula apabila variabel bebas mengalami kenaikan, maka variabel terikat juga akan ikut meningkat.

\section{Hasil Koefisien Determinasi}

Besarnya persentase variabel independen dapat menjelaskan variabel dependen dapat diketahui dari besarnya nilai koefisien determinasi yang sudah disesuaikan (Adjusted $\mathrm{R}$ Square). Hasil perhitungan dengan 
menggunakan SPSS versi 24. diperoleh hasil

sebagai berikut :

Tabel 10 : Hasil Koefisien Determinasi

Model Summary ${ }^{b}$

\begin{tabular}{lcrrrr}
\hline & & $\mathrm{R}$ & Adjusted & Std. Error of & Durbin- \\
Model & $\mathrm{R}$ & Square & R Square & the Estimate & Watson \\
\hline 1 & $.916^{\mathrm{a}}$ & .839 & .803 & 2.771 & 2.131 \\
\hline
\end{tabular}

Sumber : hasil pengolahan SPSS 24.0

Berdasarkan Tabel 10. diperoleh nilai koefisien determinasi sebesar 0.839 yang berarti besarnya pengaruh Pengembangan produk dan Media sosial terhadap keputusan pembelian adalah sebesar $83,9 \%$ dan sisanya adalah sebesar $16,1 \%$ dipengaruhi oleh faktor lain yang tidak disertakan dalam penelitian.

\section{Hasil Uji Hipotesis}

Hasil Uji Hipotesis Secara Parsial ( Uji t)

Uji t digunakan untuk mengetahui apakah pengaruh masing-masing $\mathrm{V}$ ariabel bebas terhadap variabel terikatnya signifikan atau tidak.

Di bawah ini disajikan dalam tabel 4.25 pengujian hipotesis parsial sebagai berikut:

\section{Tabel 11 : Hasil Uji Parsial (Uji t)}

Coefficients $^{\mathrm{a}}$

\begin{tabular}{|c|c|c|c|c|c|c|}
\hline \multirow{2}{*}{\multicolumn{2}{|c|}{ Model }} & \multicolumn{2}{|c|}{$\begin{array}{l}\text { Unstandardized } \\
\text { Coefficients }\end{array}$} & \multirow{2}{*}{$\begin{array}{c}\begin{array}{c}\text { Standardized } \\
\text { Coefficients }\end{array} \\
\text { Beta }\end{array}$} & \multirow[t]{2}{*}{$\mathrm{t}$} & \multirow[t]{2}{*}{ Sig. } \\
\hline & & $\mathrm{B}$ & Std. Error & & & \\
\hline \multirow[t]{3}{*}{1} & (Constant) & 2.402 & 1.612 & & 1.490 & .140 \\
\hline & $\begin{array}{l}\text { Pengembangan } \\
\text { Produk }\end{array}$ & .219 & .094 & .180 & 2.343 & .021 \\
\hline & Mesia Sosial & .700 & .074 & .722 & 9.397 & .000 \\
\hline
\end{tabular}

a. Dependent Variable: Keputusan Pembelian

Sumber : hasil pengolahan SPSS 24.0

Interprestasi hasil dari pengujian hipotesis secara parsial diatas untuk masing- masing variabel independen adalah sebagai berikut:

\section{Pengaruh Pengembangan Produk}

\section{Terhadap Keputusan Pembelian}

Hasil uji $\mathrm{t}$ untuk variabel pengembangan produk menunjukkan nilai signifikasi $0.021<$ 0.05 dan thitung sebesar 2.343 yang berarti lebih besar dari nilai t-tabel (1.66123) maka pada tingkat kekeliruan 5\% dapat disimpulkan bahwa H1 diterima, 
besar dari nilai ttabel(1.66123) maka pada tingkat kekeliruan 5\% dapat disimpulkan bahwa $\mathrm{H} 2$ diterima,

\section{Uji Hipotesis Secara Simultan (Uji f)}

Uji f (F-test) dimaksudkan untuk mengetahui pengaruh variabel-variabel independen (Pengembangan Produk dan Media Sosial) secara simultan (bersama- sama) terhadap variabel tak bebas (Keputusan Pembelian).

Tabel 12 : Hasil Uji Simultan

\begin{tabular}{|c|c|c|c|c|c|c|}
\hline \multicolumn{7}{|c|}{ ANOVA $^{\mathrm{a}}$} \\
\hline Model & & Sum of Squares & df & Mean Square & $\mathrm{F}$ & Sig. \\
\hline \multirow[t]{3}{*}{1} & Regression & 1796.336 & 2 & 898.168 & 134.746 & $.000^{\mathrm{b}}$ \\
\hline & Residual & 619.903 & 93 & 6.666 & & \\
\hline & Total & 2416.240 & 95 & & & \\
\hline
\end{tabular}

a. Dependent Variable: Keputusan Pembelian

Berdasarkan tabel 11 diatas hasil uji $\mathrm{F}$ menunjukkan bahwa secara simultan terdapat pengaruh yang positif dan signifikan antara Pengembangan produk dan media sosial terhadap keputusan pembelian. Ini terlihat dari nilai Fhitung sebesar 134,746 yang lebih besar dari nilai Ftabel sebesar 3.09.

\section{KESIMPULAN DAN SARAN}

\section{Kesimpulan}

Hasil penelitian menunjukkan bahwa terdapat pengaruh yang positif pada pengembangan produk terhadap keputusan pembelian dengan nilai signifikasi $0.021<0.05$ dan thitung sebesar 2.343, terdapat pengaruh yang positif media sosial terhadap keputusan pembelian dengan nilai signifkan $0.000<0.05$ dan thitung sebesar 9.397. Nilai Fhitung sebesar 134,746 nilai ini menjadi statistik uji yang akan dibandingkan dengan nilai $\mathrm{F}$ dari tabel dimana pada tabel $\mathrm{F}$ untuk $\alpha=0,05$ yaitu sebesar 3,09. Karena Fhitung 134,746 yang diperoleh lebih besar dibanding Ftabel $(3,09)$ dan hasil uji statistik pada tingkat signifikasi 0,05 dengan nilai 0.000 tersebut sesuai dengan kriteria pengujian hipotesis.

\section{Saran}

Adapun saran yang dapat peneliti sampaikan pengembangan produk menjadi suatu keharusan untuk terus dilakukan agar menjadi daya tarik bagi pelanggan dalam proses pengambilan keputusan. Media sosial dapat digunakan sebagai alat komunikasi dua arah dengan konsumen dalam mempromosikan produk-produk baru hasil dari pengembangan.

\section{DAFTAR PUSTAKA}

[1] M. N. Khuong and H. T. M. Duyen, "Personal Factors Affecting Consumer Purchase Decision towards Men Skin Care Products - A Study in Ho Chi Minh City, Vietnam," Int. J. Trade, Econ. Financ., vol. 7, no. 2, pp. 44-50, 2016 ,

doi: 10.18178/ijtef.2016.7.2.497. 
[2] Sujani, "Pengaruh Perilaku Konsumen Terhadap Keputusan Belanja Di Indomaret," J. Ekon. dan Bisnis Univ. Wijaya Putra, no. 1411-9501, pp. 191-205, 2017.

[3] B. Foster, "Impact of Brand Image on Purchasing Decision on Mineral Water Product 'Amidis' (Case Study on Bintang Trading Company)," Am. Res. J. Humanit. Soc. Sci., vol. 2, no. 1, pp. 1-11, 2017, doi: 10.21694/23787031.16023 .

[4] L. Lahindah, M. Merisa, and R. A. Siahaan, "The Influence of Product Innovation and Service Quality to Buying Decision and The Impacts to Repeat Buying at Progo Road bandung," Asian J. Technol. Manag., vol. 11, no. No. 2, pp. 118-124, 2018, [Online]. Available: https://doi.org/10.1016/j.heliyon.2020 .e04912.

[5] M. Ginting and H. Sembiring, "The Effect of Product Innovation, Product Quality And City Image on Purchase Decision of Uis Karo Woven Fabric," Adv. Econ. Bus. Manag. Res., vol. 46, no. Ebic 2017, pp. 593-598, 2018, doi: 10.2991/ebic-17.2018.94.

[6] A. Stankevich, "Explaining the Consumer Decision-Making Process: Critical Literature Review," J. Int. Bus. Res. Mark., vol. 2, no. 6, pp. 7-14, 2017, doi: 10.18775/jibrm.18498558.2015.26.3001.

[7] F. Jashari and V. Rrustemi, "The Impact of Social Media on Consumer Behavior in Kosovo," SSRN Electron.
J., vol. VII, no. 1, pp. 1-21, 2016, doi: $10.2139 /$ ssrn.2850995.

[8] D. Voramontri and L. Klieb, "Impact of social media on consumer behaviour," Int. J. Inf. Decis. Sci., vol. 11, no. 3, pp. 209-233, 2019, doi: 10.1504/IJIDS.2019.101994.

[9] F. Sudirjo, "Social Media, Consumer Motivation, And Consumer Purchase Decision For Fashion Consumers In Semarang District," J. Manaj., vol. 12, no. 1 , p. 78,2021 , doi: $10.32832 / \mathrm{jm}-$ uika.v12i1.3985.

[10] I. H. Hatta, W. Rachbini, and S. Parenrengi, "Analysis of product innovation, product quality, promotion, and price, and purchase decisions," South East Asia J. Contemp. Bus., vol. 16, no. 5, pp. 183189, 2018.

[11] S. Qazzafi, "Consumer Buying Decision Process Toward Products," Int. J. Sci. Res. Eng. Dev., vol. 2, no. 5,September, 2019.

[12] F. Yogesh and M. Yesha, "Effect of Social Media on Purchase Decision," Pacific Bus. Rev. Int., vol. 6, no. 11, 2014, doi: 10.3126/pravaha.v25i1.31955.

[13] K. Hutter, J. Hautz, S. Dennhardt, and J. Füller, "The impact of user interactions in social media on brand awareness and purchase intention: The case of MINI on Facebook," J. Prod. Brand Manag., vol. 22, no. 5, pp. 342351, 2013, doi: 10.1108/JPBM-052013-0299. 